\title{
BMJ Open Effects of family planning factors on the awareness of sexual and reproductive healthcare rights among married women of reproductive age in China: a cross sectional study
}

Wu Junqing, ${ }^{1,2}$ Yu Chuanning, ${ }^{1,2}$ Li Yuyan ${ }^{1,2}$

To cite: Junqing $W$,

Chuanning Y, Yuyan L. Effects of family planning factors on the awareness of sexual and reproductive healthcare rights among married women of reproductive age in China: a cross sectional study. BMJ Open 2017;7:e017621. doi:10.1136/ bmjopen-2017-017621

- Prepublication history and additional material for this paper are available online. To view please visit the journal (http:// dx.doi.org/10.1136/bmjopen2017-017621).

WJ and YC contributed equally.

Received 9 May 2017

Revised 28 August 2017

Accepted 29 August 2017

CrossMark

${ }^{1}$ School of Public Health of Fudan University, Shanghai, China

${ }^{2}$ Department of Epidemiology and Social Science on Reproductive Health, Shanghai Institute of Planned Parenthood Research/WHO Collaborating Centre for Research in Human Reproduction Unit of Epidemiology, Shanghai, China

Correspondence to

Dr Wu Junqing;

wujq1688@163.com

\section{ABSTRACT}

Objectives Although family planning in China has changed gradually since 1994, there are few studies about family planning and women's reproductive rights. The main objective of this study was to examine awareness of sexual and reproductive healthcare rights (SRHCRs), and learn how factors related to family planning influence awareness of SRHCRs among married women of reproductive age in China.

Methods and participants Inner Mongolia, Chongqing, Guangdong and Henan were selected for the study, and a total of 2504 married women of reproductive age were recruited. A self-administered anonymous questionnaire was used to collect information on participants' awareness of SRHCRs.

Results There were a total of $10843(\leq 6 \times 2504)$ responses, with a response rate of $72.17 \%$ (10 843/15 024) on average among participants regarding SRHCRs (a multiple response set). The highest response rate was for choice (Right 3) $(90.64 \%, 95 \% \mathrm{Cl} 89.47 \%$, $91.81 \%)$, followed by privacy (Right 5) $(86.11 \%, 95 \% \mathrm{Cl}$ $84.72 \%, 87.50 \%)$ and information (Right 1) $(84.47 \%$, $95 \% \mathrm{Cl} 83.02 \%, 85.93 \%)$. Only $43.39 \%$ (95\% Cl $41.40 \%$, $45.38 \%$ ) of participants gave responses to safety (Right 4). Participants without children showed more interest in Right 1, in access (Right 2) and in Right 4. Those who utilised tests for fetal sex determination paid more attention to Rights 2 and 4. Women who accepted informed choice were more likely to be aware of all six rights except for Right 3 and dignity (Right 6). Those individuals who were satisfied or very satisfied with comprehensive sexual and reproductive health counselling services were more likely to show interest in all six rights.

Conclusions Awareness of SRHCRs among reproductive aged women in China is still inadequate. Family planning service providers might strengthen the service awareness of sex and reproductive health rights according to the different needs of women.

\section{INTRODUCTION}

In China, family planning has been an historical as well as an imperative choice under the specific laws guiding population and social
Strengths and limitations of this study

- This study is one of the first to examine the effects of factors related to family planning on the awareness of sexual and reproductive healthcare rights (SRHCRs) among married women of reproductive age in China.

- A multiple response set regarding SRHCRs was analysed using a generalised estimating equation.

- For this cross sectional study, causal inferences could not be established with certainty and recall bias may have occurred.

- This study was limited only to the awareness of SRHCRs. Therefore, behavioural modification towards realising these rights was not included.

development. The modern history of family planning in China can be viewed as having occurred in four stages. ${ }^{1}$ The first stage was during the early 1970 s when the government of the People's Republic of China launched a targeted family planning campaign nationwide to promote late marriage, childbearing, spacing of births and limited fertility. At that time, contraception was introduced as the main method for reducing the fertility rate. Consequently, married couples had the right to select contraceptive methods and decide birth spacing. The second stage was ushered in by the reform of the socialist market economy, along with related concerns about China's rapid population growth. Consequently, in 1979, the central government enacted the harsh mandatory one child policy. From 1980 to 1983, the mandatory long term contraceptive policy was further strengthened. ${ }^{2}$ The expanded policy severely restricted the rights of couples to have an unauthorised number of children and to select a method of contraception. For a family that had one child, the woman was required 
to be fitted with an intrauterine device. Couples who had two children were coerced into agreeing to sterilisation of one partner (yi huai er zha). Campaigns promoting abortions were also a focus.

From the middle of the 1990s to 2014, the government of the People's Republic of China instituted a third stage in the nationwide family planning effort. During this period, they established a mitigated policy that accepted the concepts of sexual and reproductive health rights (SRHRs) emphasised by the International Conference on Population and Development held in Cairo in 1994. In light of the emphasis presented by the international community, the Chinese government shifted both the range and content of family planning services from simple population control to a combination of population control and SRHRs. Currently, the fourth stage of development, from 2015 to the present, has seen full liberalisation of the second child policy. In 2015, the central government dismantled the remnants of the one child policy in view of the ageing of population and economic recession. During this period, women's reproductive rights were consolidated.

In this manner, a supportive environment for promoting women's sexual and reproductive healthcare rights (SRHCRs) was established in China that continues today. These rights are based on guidance from the International Planned Parenthood Federation (IPPF) and play an important role for family planning. This initiative also relies on a series of rules and regulations that fall within the Population and Family Planning Law of the People's Republic of China. SRHCRs embody the women centred principles of family planning services, as well as women's empowerment. In addition, as another important element in family planning services, informed choice helps women of reproductive age to express their own sexual and reproductive goals with safety and dignity, while improving the quality of family planning reproductive services and furthering women's empowerment in China.

However, there are still major challenges blocking the full realisation of women's family planning and reproductive health rights in China. On the one hand, conflicts still exist between individual rights and national policies. For example, with the continual development of society, women's desire for equality and empowerment is more urgent than ever before. However, the level of family planning services is rather low, and the service concept is still imperfect. Policies on improving such services lag behind women's desire. On the other hand, from the perspective of family planning service providers, little attention is paid to women's rights because providers may not understand women's rights, lack awareness of these rights or possibly lack the appropriate skills required by family planning services. Clearly, women of reproductive age cannot participate actively in services and maintain their rights if they do not possess sufficient knowledge of basic reproductive rights. Therefore, we urgently need to re-examine family planning and reproductive health services in China with respect to realising women's SRHCRs in family planning.

A substantial number of studies have focused on young women and induced abortions, sexually transmitted diseases/HIV or contraceptive methods. ${ }^{3-5}$ However, very few studies have addressed SRHCRs, which are important for providing useful insights into women's reproductive health. For our study, we hypothesised that six SRHCRs would correlate with some factors of family planning. Therefore, this study was designed primarily to explore awareness of these six SRHCRs among married women of reproductive age in China, and to analyse the impact of identified factors of family planning on these rights.

\section{DATA AND METHODS}

For this research, we conducted a 1 year cross sectional study (August 2013-August,2014) using a three stage stratified random sampling method for the overall sampling scheme, along with an on-site sampling scheme based on the permanent population registration system of China. The sampling design had four features. First, it drew a random sample. Second, to be representative, the scope of the selected survey sites (primary sampling units (PSUs)) included provinces, autonomous regions and municipalities. Third, the selected areas had established

\begin{tabular}{|c|c|c|}
\hline Provinces $(n=22)$ & $\begin{array}{l}\text { Autonomous regions } \\
(n=5)\end{array}$ & $\begin{array}{l}\text { Municipality } \\
(n=4)\end{array}$ \\
\hline Hebei & Inner Mongolia & Beijing \\
\hline Shangxi & Guangxi & Tianjin \\
\hline Liaoning & Xinjiang & Shanghai \\
\hline Jilin & Ningxia & Chongqing \\
\hline Heilongjiang & Tibet & \\
\hline \multicolumn{3}{|l|}{ Jiangsu } \\
\hline \multicolumn{3}{|l|}{ Zhejiang } \\
\hline \multicolumn{3}{|l|}{ Anhui } \\
\hline \multicolumn{3}{|l|}{ Fujian } \\
\hline \multicolumn{3}{|l|}{ Jiangxi } \\
\hline \multicolumn{3}{|l|}{ Shandong } \\
\hline \multicolumn{3}{|l|}{ Henan } \\
\hline \multicolumn{3}{|l|}{ Hubei } \\
\hline \multicolumn{3}{|l|}{ Hunan } \\
\hline \multicolumn{3}{|l|}{ Guangdong } \\
\hline \multicolumn{3}{|l|}{ Hainan } \\
\hline \multicolumn{3}{|l|}{ Sichuan } \\
\hline \multicolumn{3}{|l|}{ Guizhou } \\
\hline \multicolumn{3}{|l|}{ Yunnan } \\
\hline \multicolumn{3}{|l|}{ Shaanxi } \\
\hline \multicolumn{3}{|l|}{ Gansu } \\
\hline Qinghai & & \\
\hline
\end{tabular}




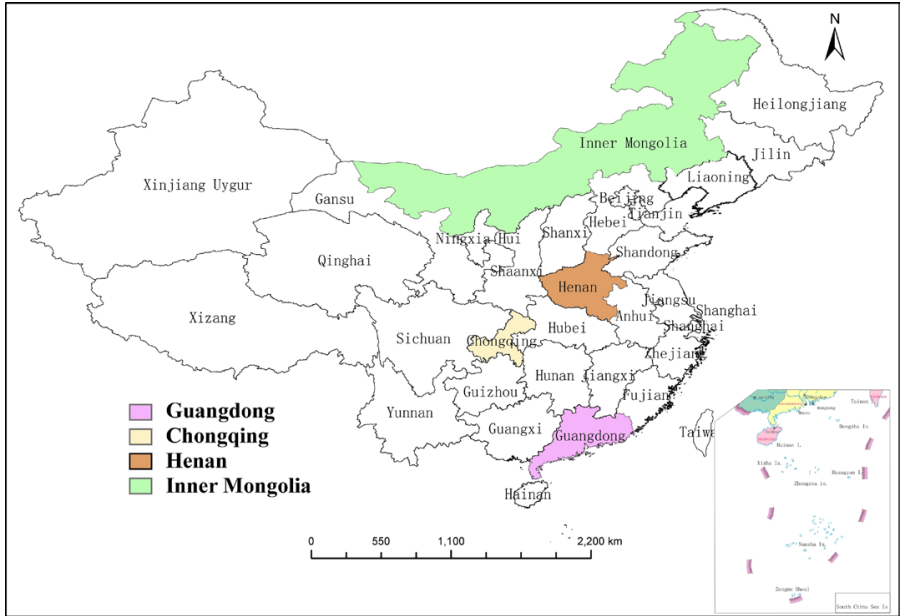

Figure 1 China's administrative units: provinces, autonomous regions and municipalities (sourced from National Atlas of Administrative Province, Area and County (City), Ministry of Land and Resources of the People's Republic of China).

a better family planning managerial and service network, and had gained strong support derived from family planning services and community workers. Fourth, all things being equal, cost minimisation for the research group was chosen.

\section{Overall sampling scheme}

The PSUs included 22 provinces, 5 autonomous regions and 4 municipalities of China (table 1 and see online supplementary appendix 1). The first stage of sampling involved selecting PSUs by probability proportionate to size. In the second stage, we selected counties from the chosen PSUs in the same way. In the third stage, we selected subjects from residential communities/sub-districts in the selected counties, using systematic sampling.

Based on these standards, four regions were selected for the study: Guangdong, Chongqing, Inner Mongolia and Henan(figure 1 and see online supplementary appendix $1)$. Two counties were selected for each city.

\section{Sample size}

For this study, the sample size was calculated using the following formula:

$$
\mathrm{N}=\operatorname{deff} \times \mathrm{u}^{2} \times \mathrm{p} \times(1-\mathrm{p}) / \delta^{2}
$$

where $\mathrm{n}$ is the parameter to be calculated-that is, the sample size in terms of the number of reproductive aged married women to be selected; deff is the sample design effect, assumed to be 2.0 (default value); $u$ is the statistic that defines the level of confidence desired, using $95 \%$ CI; and $p$ is an estimate of a key indicator to be measured by the study. Here, $p$ equals $47 \%$, and $\delta$ is the margin of error to be attained (in this case $10 \%$ ).

This approach resulted in a sample size of 866 married women of reproductive age. Therefore, across the four survey sites, the total sample size was $3465(866 \times 4)$. Inclusion criteria for eligible participants were as follows: (1) women aged 20-49 years; (2) married; (3) local permanent residents; (4) engaged in regular sexual activity; and (5) participated in this study voluntarily.

\section{Measures}

We designed the questionnaire for this study based primarily on the Population and Family Planning Law of the People's Republic of China, the Protection of Rights and Interests of Women, and the National Programme for Women's Development in China, as well as the IPPF Charter on Sexual and Reproductive Rights. The questionnaire included five main areas of focus: demographic characteristics, marital and contraceptive history, informed choice, comprehensive sexual and reproductive health (SRH) counselling, and sexual and SRHRs.

Prior to the formal survey, we conducted a pilot study to collect feedback on the questionnaire from several group discussions with married women of reproductive age. We made modifications to the questionnaire in accordance with the input gathered from these group discussions, until the questionnaire reached the goal of gathering the required data in a full and valid manner.

\section{Independent variables}

We included five sociodemographic characteristics as the controlled variables, with three reproductive history variables and three family planning service variables as the family planning related variables (table 2 ).

\section{Dependent variables}

The dependent variable tested in this study were a multiple response set that embraced six rights. The main question for the multiple response set was, 'Are you aware of the role of SRHCRs as related to the following rights?' For each right listed, interviewees had the option to select 'yes' or 'no', as shown in table 3.

\section{Data collection}

For this study, the interviewers were service providers and community workers. We provided a standardised training programme to ensure that they understood the study and the questionnaire's content, and to confirm that they had appropriate interview skills. To recruit participants, the interviewers put up posters, delivered leaflets and went 
Open Access

Table 2 Assignment and coding of independent variables

\begin{tabular}{|c|c|}
\hline Variable & Assignment and coding \\
\hline \multicolumn{2}{|l|}{ Sociodemographics characteristics } \\
\hline \multirow[t]{4}{*}{ Age (years) } & $<25=1$ \\
\hline & $25-34=2$ \\
\hline & $35-44=3$ \\
\hline & $45-49=5$ \\
\hline \multirow[t]{4}{*}{ Educational attainment } & Elementary school or lower $=1$ \\
\hline & Junior high school=2 \\
\hline & High school=3 \\
\hline & Junior college or higher $=4$ \\
\hline \multirow[t]{2}{*}{ Household registration } & Rural $=1$ \\
\hline & Urban=2 \\
\hline \multirow[t]{4}{*}{ Occupation } & Labourer/commercial/service worker $=1$ \\
\hline & Agricultural labourer $=2$ \\
\hline & Employee in public institution=3 \\
\hline & Other $=4$ \\
\hline \multirow[t]{5}{*}{ Family annual per capita income (dollars) } & $<160.78=1$ \\
\hline & $160.78-321.57=2$ \\
\hline & $321.58-482.35=3$ \\
\hline & $482.36-643.14=4$ \\
\hline & $\geq 643.15=5$ \\
\hline \multicolumn{2}{|l|}{ Reproductive history } \\
\hline \multirow[t]{4}{*}{ No of children } & $0=0$ \\
\hline & $1=1$ \\
\hline & $2=2$ \\
\hline & $\geq 3=3$ \\
\hline \multirow[t]{2}{*}{ Did you use fetal sex tests? } & Yes $=1$ \\
\hline & $\mathrm{No}=0$ \\
\hline \multirow[t]{2}{*}{ Are you using contraceptive methods? } & Yes $=1$ \\
\hline & $\mathrm{No}=0$ \\
\hline
\end{tabular}

Family planning service

Did you receive informed choice? $\quad$ Yes=1

$\mathrm{No}=2$

Satisfaction with comprehensive sex and reproductive health counselling Very satisfied $=1$

services offered by family planning workers

Satisfied $=2$

Dissatisfied $=3$

Institutes that were optimal for family planning services

Hospital=1

Maternal and child care centre $=2$

Family planning centre $=3$

Community health centre $=4$

door to door informing the residents that there was an opportunity to participate in the research for 1 month. Participants were all volunteers who were asked to complete the questionnaires in their houses or at some other designated place in their communities or near their living quarters. Participants completed the questionnaires themselves without the third parties being present. The interviewers of the same gender who were responsible for ensuring that the questionnaires were completed assisted the participants to understand the questions if they encountered difficulties. The project managers evaluated the completeness and logic of the questionnaires, 
Table 3 Multiple response set of sexual and reproductive healthcare rights

\begin{tabular}{|c|c|c|}
\hline Variable & $\begin{array}{l}\text { Assignment } \\
\text { and coding }\end{array}$ & Definition \\
\hline Information (Right 1) & yes $=1$, no $=0$ & $\begin{array}{l}\text { To know the benefits } \\
\text { and availability } \\
\text { of sexual and } \\
\text { reproductive health } \\
\text { services, and to know } \\
\text { one's rights to this } \\
\text { information. }\end{array}$ \\
\hline Access (Right 2) & & $\begin{array}{l}\text { To obtain services } \\
\text { regardless of race, sex } \\
\text { or sexual orientation, } \\
\text { marital status, age, } \\
\text { religious or political } \\
\text { beliefs, ethnicity or } \\
\text { disability }\end{array}$ \\
\hline Choice (Right 3) & & $\begin{array}{l}\text { To decide freely on } \\
\text { whether and how to } \\
\text { control one's own } \\
\text { fertility, and to choose } \\
\text { which method to use }\end{array}$ \\
\hline Safety (Right 4) & & $\begin{array}{l}\text { To be able to protect } \\
\text { oneself from unwanted } \\
\text { pregnancy, disease } \\
\text { and violence }\end{array}$ \\
\hline Privacy (Right 5) & & $\begin{array}{l}\text { To have a private } \\
\text { environment during } \\
\text { counselling and } \\
\text { services }\end{array}$ \\
\hline Dignity (Right 6) & & $\begin{array}{l}\text { To be treated with } \\
\text { respect, empathy, } \\
\text { courtesy, consideration } \\
\text { and attentiveness }\end{array}$ \\
\hline
\end{tabular}

returning feedback on errors to the investigators when unqualified questionnaires were found. The interviewers then returned to the interviewees to revise the questionnaires in a timely manner.

\section{Data analysis}

Data from the questionnaires were entered twice by different professionals using EpiData 3.1 to enable a comparison between data. Data cleaning was performed using SAS V.9.3 (SAS Inc, Cary, North Carolina, USA) to verify the consistency for all of the variables. Descriptive statistics included frequencies and proportions. A generalised estimating equation (GEE) was employed to explore the effects of influencing factors on SRHCRs ${ }^{6-8}$ (see online supplementary appendix 2).

\section{Ethical considerations}

The study protocol was approved by the research ethics committee of the Shanghai Institute of Planned Parenthood Research (code PJ2014-20) prior to the implementation of the research. We presented the aims of the study to all eligible participants, providing interpretation and clarification as needed. Before data collection was initiated, verbal and written informed consent were obtained from all participants for the purposes of information security and privacy protection. All questionnaires were completed anonymously, and before the interview, the investigators signed a confidentiality agreement to protect the privacy and sensitive information of the interviewees.

\section{RESULTS}

\section{Characteristics of participants}

In the initial study survey, 3891 participants were recruited. Of these, 135 participants were excluded from the study based on the inclusion criteria. In total, 3756 participants were included. As mentioned above, awareness of SRHCRs ('are you aware of SRHCRs') was nested in the question, 'Do you know the rights of service recipients?' Because our study was designed to survey only participants who knew of these rights, 961 respondents were excluded from further analysis based on their negative answers regarding their knowledge of the rights for service recipients. Therefore, the final number of participants included in our analysis was 2504 out of 3756 . Of this group, 2047 respondents were 25-44 years of age, accounting for $81.74 \%$ of the total. Over $40 \%$ of participants had a junior high school education, more than half (58.83\%) were rural to urban migrants and $42.69 \%$ of respondents were agricultural labourers. Nearly one-third of the families had an annual income of $\$ 643.15$ or above. Of the respondents, over half had one child, but very few had more. Among those who were ever pregnant (full term or not), $97.41 \%$ did not avail themselves of fetal tests to determine the sex of the fetus, and the majority of participants $(92.45 \%)$ reported that they used contraceptives (table 4 ).

\section{SRHCR awareness among interviewees}

There were a total of $10843(\leq 6 \times 2504)$ responses regarding SRHCRs among the participants, and the average response rate regarding awareness of SRHCRs was $72.17 \%$ (10 843/15 024). Right 3 had the highest response rate $(90.64 \%, 95 \% \mathrm{CI} 89.47 \%, 91.81 \%)$, followed by Right $5(86.11 \%, 95 \%$ CI $84.72 \%, 87.50 \%)$ and Right 1 $(84.47 \%, 95 \%$ CI $83.02 \%, 85.93 \%)$. Only $43.39 \%$ (95\% CI $41.40 \%, 45.38 \%)$ of participants gave responses to Right 4 (table 5).

\section{GEE for awareness of SRHCRs}

In the GEE model, the 6 constant estimates specify the $6 \mathrm{log}$ values of the baseline response probability/reference, respectively. Thus the response probabilities for baseline awareness of SRHCRs were calculated as $27.05 \%, 18.24 \%, 36.02 \%, 5.42 \%, 28.70 \%$ and $17.51 \%$, respectively, according to the formula $\mathrm{P}=\frac{e^{\beta_{0}}}{1+e^{\beta_{0}}}$. The response probabilities for baseline/reference awareness of SRHCRs indicated the responses regarding the references for the variables in the model (eg, with respect to age, the group age 45-49 years was the reference, and 
Table 4 Demographic characteristics and reproductive history of the study participants

\begin{tabular}{lr}
\hline Variable & No (\%) (n=2504) \\
\hline Age (years) & \\
\hline $20-25$ & $269(10.74)$ \\
\hline $25-34$ & $1027(41.01)$ \\
\hline $35-44$ & $1020(40.73)$ \\
\hline $45-49$ & $188(7.51)$ \\
\hline Educational attainment & \\
\hline Elementary school or lower & $179(7.15)$ \\
\hline Junior high school & $1035(41.33)$ \\
\hline High school & $699(27.92)$ \\
\hline Junior college or higher & $591(23.60)$ \\
\hline Household registration & \\
\hline Rural & $1473(58.83)$ \\
\hline Urban & $1031(41.17)$ \\
\hline Occupation & \\
\hline Labourer/commercial/service worker & $370(14.78)$ \\
\hline Peasant & $1069(42.69)$ \\
\hline Employer in public institution & $309(12.34)$ \\
\hline Other & $756(30.19)$ \\
\hline Family annual per capita income (dollars) & \\
\hline$<160.78$ & $304(12.14)$ \\
\hline $160.78-321.57$ & $353(14.10)$ \\
\hline $321.58-482.35$ & $567(22.64)$ \\
\hline $482.36-643.14$ & $514(20.53)$ \\
\hline$\geq 643.15$ & $766(30.59)$ \\
\hline No of children & \\
\hline 0 & $2414(32.51)$ \\
\hline 1 & $291(11.62)$ \\
\hline 2 & $8(0.32)$ \\
\hline Used fetal sex tests & \\
\hline Yes & \\
\hline No & \\
\hline
\end{tabular}

the response represented this reference for 45-49 years of age). Although the response probabilities were not of practical significance, the estimates showed a consistent trend for the proportions in table 5 .

Awareness of SRHCRs was correlated with region, age, educational attainment, annual family income per person, number of children, whether the couple used fetal sex prediction tests and whether they accepted informed choice and were satisfied with the comprehensive SRH counselling offered by family planning workers (FPWs).
Table 5 Distribution of awareness of sexual and reproductive healthcare rights based on multiple responses among interviewees $(n=2504)$

\begin{tabular}{lll}
\hline Rights & $\%$ & $95 \%$ Cl (\%) \\
\hline Information (Right 1) & 84.47 & $(83.02,85.93)$ \\
Access (Right 2) & 75.70 & $(73.98,77.43)$ \\
Choice (Right 3) & 90.64 & $(89.47,91.81)$ \\
Safety (Right 4) & 43.39 & $(41.40,45.38)$ \\
Privacy (Right 5) & 86.11 & $(84.72,87.50)$ \\
\hline Dignity (Right 6) & 74.70 & $(72.95,76.44)$ \\
\hline
\end{tabular}

Participants without children were correlated with higher odds of responses on SRHCRs in comparison with those who had three or more children. The odds of awareness of SRHCRs among participants who used fetal sex prediction tests were higher than among those who did not use fetal sex tests. The odds of awareness of SRHCRs among those who accepted informed choice were threefold greater compared with those who did not $(\mathrm{OR}=3.35$; 95\% CI 2.74 to 4.09 ). Participants who were very satisfied or satisfied with comprehensive SRH counselling offered by FPWs were significantly more likely to be aware of SRHCRs (table 6).

On further analysis, we assigned the six separate options (constants) to factors that significantly influenced family planning (table 6). Compared with participants who had two or more children, those without children were more likely to be interested in Rights 1, 2 and 4. Participants who used fetal sex tests were more likely to focus on Right 2 and Right 4 than those who never used such tests. Women who received informed choice were more likely to respond to all of the rights except for Rights 3 and 6 , compared with those who never accepted informed choice. Participants who were satisfied or very satisfied with comprehensive SRH counselling offered by FPWs versus those who were dissatisfied with such counselling were more likely to show interest in all of the rights (table 7).

\section{DISCUSSION}

\section{Awareness of SRHCRs in China}

Our research showed that the general level of awareness of SRHCRs was relatively low, averaging a $72.17 \%$ response rate among participants. Previous research on the extent of awareness regarding general health rights in China is still sparse, ${ }^{9} 10$ and variations in awareness of SRHCRs exist among women generally. ${ }^{11}$ Previous research demonstrated that women manifested various levels of awareness of SRHCRs based on factors such as age, income, education and geographic location. ${ }^{12-14}$ A similar result was found in our study. Although the subjective awareness of rights among Chinese women has improved, the long term impact of feudal and cultural contexts has not been eliminated completely, and these 
Table 6 Generalised estimating equation for the correlation between the factors and sexual and reproductive healthcare rights in participants $(n=2504)$

\begin{tabular}{|c|c|c|c|c|c|}
\hline Parameter & Estimate & SE & p Value & OR & $(95 \% \mathrm{Cl})$ \\
\hline Int1 & -1.00 & 0.37 & 0.0071 & & \\
\hline Int2 & -1.50 & 0.37 & $<0.0001$ & & \\
\hline Int3 & -0.57 & 0.37 & 0.1278 & & \\
\hline Int4 & -2.86 & 0.38 & $<0.0001$ & & \\
\hline Int5 & -0.91 & 0.38 & 0.0149 & & \\
\hline Int6 & -1.55 & 0.37 & $<0.0001$ & & \\
\hline \multicolumn{6}{|l|}{ Region } \\
\hline Inner Mongolia & -0.51 & 0.09 & $<0.0001$ & 0.60 & (0.50 to 0.71$)$ \\
\hline Guang Zhou & -0.37 & 0.10 & $<0.0001$ & 0.69 & (0.57 to 0.83$)$ \\
\hline He Nan & Ref & & & 1 & \\
\hline \multicolumn{6}{|l|}{ Age (years) } \\
\hline$<25$ & 0.66 & 0.14 & $<0.0001$ & 1.94 & (1.47 to 2.57$)$ \\
\hline $25-34$ & 0.25 & 0.11 & 0.0221 & 1.28 & (1.04 to 1.58$)$ \\
\hline $45-49$ & Ref & & & 1 & \\
\hline \multicolumn{6}{|l|}{ Educational attainment } \\
\hline Elementary school or lower & -0.56 & 0.15 & 0.0001 & 0.57 & (0.43 to 0.76$)$ \\
\hline Junior high school & -0.57 & 0.11 & $<0.0001$ & 0.57 & (0.46 to 0.70$)$ \\
\hline High school & -0.39 & 0.10 & 0.0001 & 0.68 & (0.55 to 0.82$)$ \\
\hline Junior college or higher & Ref & & & 1 & \\
\hline \multicolumn{6}{|c|}{ Annual family per capita income (dollars) } \\
\hline$<160.78$ & 0.44 & 0.10 & $<0.0001$ & 1.56 & (1.27 to 1.89$)$ \\
\hline$\geq 643.15$ & Ref & & & 1 & \\
\hline \multicolumn{6}{|l|}{ No of children } \\
\hline 0 & 0.23 & 0.10 & 0.0251 & 1.26 & (1.03 to 1.55$)$ \\
\hline 2 & Ref & & & 1 & \\
\hline \multicolumn{6}{|l|}{ Did you use fetal sex tests? } \\
\hline Yes & 0.57 & 0.20 & 0.0046 & 1.78 & (1.20 to 2.65$)$ \\
\hline No & Ref & & & 1 & \\
\hline \multicolumn{6}{|l|}{ Did you receive informed choice? } \\
\hline Yes & 1.21 & 0.10 & $<0.0001$ & 3.35 & (2.74 to 4.09$)$ \\
\hline No & Ref & & & 1 & \\
\hline \multicolumn{6}{|c|}{$\begin{array}{l}\text { Satisfaction with comprehensive sexual and reproductive } \\
\text { health counselling offered by family planning workers }\end{array}$} \\
\hline Very satisfied & 1.03 & 0.18 & $<0.0001$ & 2.82 & (1.98 to 4.01$)$ \\
\hline Satisfied & 0.81 & 0.18 & $<0.0001$ & 2.26 & (1.58 to 3.24 ) \\
\hline Dissatisfied & Ref & & & 1 & \\
\hline
\end{tabular}

Int1-In6 were the six conditions of the probabilities of the six baseline/reference responses (see online supplementary appendix 2).

The non-significant categories in the independent variables were omitted.

influences still affect Chinese thinking and behaviour. Moreover, family planning services have shown weakness in delivering health related medical information and knowledge of family planning/reproductive health rights. In such cases, women are vulnerable when service providers neglect their autonomy. Even when they sensed inappropriateness or dissatisfaction, women were likely to be passively compliant in response to the advice or requests of service providers. ${ }^{12}$ Additionally, a crisis in trust due to the asymmetry of rights related knowledge between service providers and clients could occur, ${ }^{13}$ and such differences could be worsened further with regard to the communication of both women and service providers. Women tended to emphasise informed compliance, but then overlooked rights closely related to their own interests, ${ }^{14}$ which means that women just do what the 
Table 7 Effects of predominant influencing factors on awareness of sexual and reproductive healthcare rights $(n=2504)$

\begin{tabular}{|c|c|c|c|c|c|c|}
\hline Parameter & & Estimate & $\begin{array}{l}\text { Estimate } \\
\text { error }\end{array}$ & p Value & OR & $(95 \% \mathrm{Cl})$ \\
\hline \multicolumn{7}{|l|}{ Did you use fetal sex tests? } \\
\hline \multirow[t]{2}{*}{ Yes vs no at } & Right 2 & 1.32 & 0.42 & 0.0017 & 3.75 & (1.64 to 8.58$)$ \\
\hline & Right 4 & 0.56 & 0.26 & 0.0328 & 1.76 & (1.05 to 2.95$)$ \\
\hline \multicolumn{7}{|l|}{ No of children } \\
\hline \multirow[t]{3}{*}{0 vs 2 at } & Right 1 & -0.46 & 0.13 & 0.0004 & 0.63 & (0.49 to 0.81$)$ \\
\hline & Right 2 & -0.49 & 0.13 & 0.0002 & 0.61 & (0.47 to 0.79$)$ \\
\hline & Right 4 & 0.96 & 0.13 & $<0.0001$ & 2.62 & (2.04 to 3.38$)$ \\
\hline \multicolumn{7}{|c|}{ Did you receive informed choice? } \\
\hline \multirow[t]{4}{*}{ Yes vs no at } & Right 1 & 4.55 & 0.25 & $<0.0001$ & 94.75 & (58.32 to 153.92$)$ \\
\hline & Right 2 & 0.80 & 0.15 & $<0.0001$ & 2.22 & (1.66 to 2.98$)$ \\
\hline & Right 4 & -0.75 & 0.15 & $<0.0001$ & 0.47 & (0.35 to 0.63$)$ \\
\hline & Right 5 & 0.91 & 0.16 & $<0.0001$ & 2.49 & (1.81 to 3.41$)$ \\
\hline \multicolumn{7}{|c|}{ Satisfaction with comprehensive sexual and reproductive health counselling offered by family planning workers } \\
\hline \multirow[t]{6}{*}{ Very satisfied vs dissatisfied } & Right 1 & 0.81 & 0.27 & 0.0028 & 2.25 & (1.32 to 3.84$)$ \\
\hline & Right 2 & 0.56 & 0.27 & 0.0382 & 1.76 & (1.03 to 3.00$)$ \\
\hline & Right 3 & 0.89 & 0.32 & 0.0049 & 2.43 & (1.31 to 4.51 ) \\
\hline & Right 4 & 1.68 & 0.34 & $<0.0001$ & 5.34 & (2.74 to 10.41 ) \\
\hline & Right 5 & 0.92 & 0.29 & 0.0014 & 2.52 & (1.43 to 4.43$)$ \\
\hline & Right 6 & 0.89 & 0.28 & 0.0017 & 2.42 & (1.40 to 4.21$)$ \\
\hline \multirow[t]{6}{*}{ Satisfied vs dissatisfied } & Right 1 & 0.68 & 0.28 & 0.0168 & 1.97 & (1.13 to 3.45$)$ \\
\hline & Right 2 & 0.61 & 0.28 & 0.0308 & 1.84 & (1.06 to 3.21$)$ \\
\hline & Right 3 & 0.94 & 0.34 & 0.0049 & 2.57 & (1.33 to 4.95$)$ \\
\hline & Right 4 & 1.24 & 0.35 & 0.0004 & 3.46 & (1.75 to 6.84 ) \\
\hline & Right 5 & 1.25 & 0.31 & $<0.0001$ & 3.50 & (1.92 to 6.38$)$ \\
\hline & Right 6 & 0.72 & 0.29 & 0.0142 & 2.05 & (1.15 to 3.62$)$ \\
\hline
\end{tabular}

The non-significant constants and variables were omitted. The analysis controlled for region, age, household registration, educational attainment, occupation, annual family income per capita, contraceptive status, experience with fetal sex tests, acceptance of informed choice, satisfaction with comprehensive sexual and reproductive health counselling offered by family planning workers and the type of institution that was optimal for delivering family planning services.

service providers told them to do, but cannot strive for rights which benefit them.

\section{Family planning related factors and awareness of SRHCRs}

In China, the policy of 'late marriage and late childbirth' has been advocated by the government for years. ${ }^{15}$ In our study, women of reproductive age were 22-44 years old. As a woman's age increases, the risks of childbirth also increase, so these women could have increased concerns about their reproductive health.

Prior research ${ }^{16}$ indicated that $76.67 \%$ of married women were aware of general genital tract care, as well as genital tract care during menstrual periods and after intercourse. Half of them knew about the symptoms of genital tract infection. Only $16.25 \%$ of participants paid attention to their access to information about contraception and reproductive technology. In our study, participants who had no children showed a more positive result in terms of the issue of their reproductive health (right to safety), but a more negative result concerning information and access rights, a finding similar to the results of previous studies.

Informed choice includes the rights of men and women to be informed about reproductive health, and to have access to their choice of safe, effective, affordable and acceptable methods of family planning. ${ }^{17}$ In 1995 , informed choice was introduced to China and implemented in pilot counties that provided high quality care with respect to family planning. ${ }^{18}$ Informed choice was included in the Law of Population and Family Planning of the People's Republic of China enacted in 2001, emphasising the right of sexual equality in childbearing, and the right to information about family planning, reproductive health and education. Enfolding women's reproductive rights into a new era of family planning, informed choice reflected the practice of women's empowerment in reproductive health programme. ${ }^{19}$ 
In our study, informed choice provided an impetus towards improving three rights (Rights 1,2 and 5), but was an impediment to Right 4 . This finding indicated that women of reproductive age in China were aware of the information on sexual and reproductive health services, access to these services and the means for protecting their privacy via informed choice. However, women of reproductive age were still passive as far as selecting effective, safe and acceptable contraceptive methods. ${ }^{20}$ This result implies that it is essential to strengthen their willingness to take action based on their right to self-determination regarding contraceptive methods when implementing informed choice.

Comprehensive SRH counselling services support their clients' informed and voluntary decisions, and assist them in making a feasible plan for reproductive care and related health services. ${ }^{21}$ This approach can revitalise contraceptive methods for clients, prevent sexually transmitted diseases/HIV infections, and provide support for treatment of future sexual dysfunction, ${ }^{22-29}$ suggesting that women's SRHCRs are being heeded. With the passing of time, people will require access to integrated SRH services more than ever before. ${ }^{30}$ The core concept of comprehensive SRH counselling services is 'client oriented'. Therefore, not only is client satisfaction with these services a key measurement of quality, it also affects the utilisation of services and SRHCRs. To a great extent, the full practice of SRHCRs depends on active acceptance by clients.

Simultaneously, such acceptance relies on satisfaction with comprehensive SRH counselling services. ${ }^{31}$ Research demonstrated that even when health services were readily available and affordable, women were still not willing to use them if they were of poor quality. ${ }^{32}$ Our findings agreed with these previous studies, and also with a Chinese study demonstrating that the higher the satisfaction with reproductive health services, the stronger the acceptance of reproductive health related knowledge. ${ }^{33}$

There is an old Chinese proverb that can be translated as, 'Bring up sons to care for parents in their old age'. In the transition from traditional concepts to contemporary family planning, Chinese married women still face a decision about whether to have boys or girls when they are ready for childbearing. Although the use of fetal sex prediction tests is illegal in China, the current reality is still problematic. When performed, sexual selection generally is prejudicial against the birth of girls, and thus violates the right to non-discrimination on the basis of gender. However, modern human rights practice also reacts against forcing a woman to maintain a pregnancy against her will. A woman's right to select for pregnancy continuation or termination is among the same inalienable rights that allow her to create a family of her choice, gather information and benefit from scientific progress. ${ }^{34}$ This position is of paramount importance with respect to the current family planning policy in China, especially for those women who have had one child, or who want a boy as the first child. Therefore, increased awareness of such rights of access will be a step towards meeting their reproductive demands, and ensuring their reproductive health in a way that allows women to gain dignity. However, securing social acceptance or family position is another issue entirely.

Our study had several limitations. First, causal inferences could not be established with certainty, as ours was a cross sectional study. Second, our findings might involve selection bias. However, as estimated by a Heckman selection model, the rho (the correlation coefficient between the latent model and selection model) was not significant $(p>0.05)$. Therefore, selection bias in our study could be considered non-existent. However, recall bias may have occurred. Third, this study was limited to awareness of SRHCRs. Therefore, the significance of behavioural modification towards realising these rights was not included. Further studies need to be implemented to achieve this goal. As such, interpreting and generalising these results should be conducted scrupulously. However, we used probability proportionate to size to sample married women in various cities as a representative study population, since the family planning factors and SRHCRs were selected for married women of reproductive age. Therefore, the results could be extrapolated to married reproductive aged women across China to a reasonable extent.

\section{CONCLUSIONS}

Our study provided a picture of the awareness of SRHCRs among women of reproductive age in China. We explored the effects of selected family planning factors on awareness of SRHCRs by mining data gathered from our questionnaire. According to our results, awareness of SRHCRs among reproductive aged women in China is still inadequate. Family planning service providers can strengthen service awareness of reproductive rights according to the different needs of women.

With the transition of family planning policy, we found that the related factors of family planning had different effects on each of the SRHCRs. At present, the policy allowing a second child is available to couples in China, so informed choice has a full function, and married women can decide whether to pursue childbirth. Our research demonstrated that informed choice had significant effects on the awareness of SRHCRs. Satisfaction with comprehensive SRH counselling offered by FPWs had a positive effect on the awareness of all six SRHCRs. These findings provide some important leads for improving the awareness and application of SRHCRs.

Acknowledgements We are grateful to other investigators for contributions to our research project, including interviewers and study participants who, with understanding and patience, cooperated with the study team.

Contributors WJ conceived the study, participated in the design of the study, interpreted the results and translated them into policy suggestions. YC performed the statistical analysis, participated in interpretation of the results and drafted the manuscript. LY took part in the discussion of the paper and approved the final manuscript. 
Funding This project was funded by the National 12th Five-Year Plan (No. 2012BAI32B08).

Competing interests None declared.

Ethics approval The study was approved by the research ethics committee of the Shanghai Institute of Planned Parenthood Research (code PJ2014-20).

Provenance and peer review Not commissioned; externally peer reviewed. Data sharing statement There are no unpublished data from the study.

Open Access This is an Open Access article distributed in accordance with the Creative Commons Attribution Non Commercial (CC BY-NC 4.0) license, which permits others to distribute, remix, adapt, build upon this work non-commercially, and license their derivative works on different terms, provided the original work is properly cited and the use is non-commercial. See: http://creativecommons.org/ licenses/by-nc/4.0/

(c) Article author(s) (or their employer(s) unless otherwise stated in the text of the article) 2017. All rights reserved. No commercial use is permitted unless otherwise expressly granted.

\section{REFERENCES}

1. Wang C. History of the Chinese Family Planning program: 1970 2010. Contraception 2012;85:563-9.

2. Zhang W, Cao X. Family Planning During Economic Reform Era. Transition and Challenge: China's Population at the Beginning of the 21st Century. Oxford: Oxford University Press, 2006.

3. Orza L, Crone T, Mellin J, et al. Searching for the Second R in sexual and reproductive health and rights. J Adolesent Health 2017;60:S10-14.

4. Siegfried N, Narasimhan M, Kennedy CE, et al. Using GRADE as a framework to guide research on the sexual and reproductive health and rights (SRHR) of women living with HIV - methodological opportunities and challenges. AIDS Care 2017;29:1-6.

5. Wang $\mathrm{C}$. The impact of the state's abortion policy on induced abortion among married women in China: a mixed methods study. Chin Sociol Rev 2017:1-24

6. Wentong Z, Xiaoyan T. Application of generalized estimating equations in analysis of multiple response. Chin $\mathrm{J}$ Health Stat 2004;21:139-41.

7. Rongtao $\mathrm{H}$, Weihua $\mathrm{C}$, Jianming $\mathrm{O}$. Statistical analysis for multiple response data in the field investigation. Chin $J$ Health Stat 2009;26:595-8.

8. Min Z, Yancai L, Yongli Y. et a1. Statistical analysis for hypertensive complications using generalized estimating equations. Chin $\mathrm{J}$ Health Stat 2013;30:647-53.

9. Yc X, Wan XR, An L. Analysis of the protection knowledge about one's own rights and the perception in practice for patients. Chin Med Ethics 2006;19:58-61.

10. $L p L$, Zhang $L Z$. The research on protecting rights among patients in hospitals. Chin J Nurs 2002;37:936-7.

11. Zhang KN, Tian LC, Deng R. Migrants' awareness and related factors of their reproductive health rights in kunming city. Chin J Public Health 2008;24:97-8.

12. World Health Organization. Social determinants of sexual and reproductive health: Informing future research and programme implementation. 2010. http://www.ncdsv.org/images/WHO SocialDeterminantsSexualHealth_2010.pdf (accessed 5 Sep 2014).

13. Kavanaugh ML, Jerman J, Hubacher D, et al. Characteristics of women in the United States who use long-acting reversible contraceptive methods. Obstet Gynecol 2011;117:1349-57.
14. Crissman HP, Adanu RM, Harlow SD. Women's sexual empowerment and contraceptive use in Ghana. Stud Fam Plann 2012;43:201-12.

15. Jian $S$, Jingwen $Z$. Parity, timing of birth, and fertility: A comparative study on the trends and differential mechanism of the mean age at childbearing in China, Japan and Korea. Population Res 2017;41:3-14.

16. Shuting Z, Li Y, Li L. Investigation of reproductive health of female at reproductive age. Chin J Hum Sexuality 2017;26:132-7.

17. Yy L, Zhou Y, Zhao HX, et al. Survey on the fertility desire of married migrants in three cities of china: analysis of the desired children number. $J$ Int Reprod Health Fam Planning 2012;31:189-92

18. Globaltimes.cn: Overhaul family planning policy, say experts - Globa Times. 2015 http://www.globaltimes.cn/content/913483.shtml (accessed 28 Mar 2015)

19. Cook RJ,, Dickens BM, Fathalla MF. Reproductive health \& human rights: integrating medicine, ethics \& law. Oxford: Clarendon Press, 2003.

20. Pei HB. Study of the promotion of family planning and reproductive health right and its influence to quality of care. Shanghai, China: Doctoral Dissertation, Fudan University, 2012.

21. ILGA Europe: The International United Nations Conference on Population and Development. Cairo 1994 https://www.k4health.org/ sites/default/files/34-371\%20ICPD.pdf (accessed 2 Apr 2015).

22. Jq W, Zhang SK. The sexual and reproductive management and service among migrant population in China. 1st ed. Shanghai: Shanghai Science and Technology Publishing House, 2015:117-20.

23. kai-Ning Zhang. Reorienting concepts and methodology: the 30 years SRH in China. 1st ed. Beijing: The Social Science Academic Press, 2008.

24. Engenderhealth.org:. Comprehensive counseling for reproductive health: an integrated curriculum, 2003. https://www.engenderhealth. org/pubs/counseling-informed-choice/comprehensive-counselingfor-rh.php (accessed 5 May 2015).

25. Shah MA, Shah NM, Chowdhury RI, et al. Unmet need for contraception in Kuwait: issues for health care providers. Soc Sci Med 2004;59:1573-80.

26. Isaacs JN, Creinin MD. Miscommunication between healthcare providers and patients may result in unplanned pregnancies. Contraception 2003;68:373-6.

27. Boise R, Petersen R, Curtis KM, et al. Reproductive health counseling at pregnancy testing: a pilot study. Contraception 2003;68:377-83.

28. Oumeish OY, Oumeish IF. Community understanding and prevention of sexually transmitted diseases. Clin Dermatol 2004;22:533-6.

29. Devan GS. An overview of sexual counselling. Ann Acad Med Singapore 1995;24:732-5.

30. Bischof K. [Men and women-aspects of sexological counseling in the aging]. Ther Umsch 2005;62:807-11.

31. Zhao LJ, Che Y, Hong L, et al. Effects of integrative extension of contraceptive methods on the satisfaction of family planning among rural reproductive aged women. Chin J Fam Planning 2008;16:522-5.

32. World Bank Discussion Paper. Women's health and nutrition: making a difference. http://www-wds.worldbank.org/servlet/ WDSContentServer/WDSP/IB/1994/07/01/000009265 3970311123950/Rendered/PDF/multiOpage.pdf (accessed 8 Aug 2015).

33. Fang LW, $\mathrm{Ht} \mathrm{H}$, Zhao BG, et al. The satisfaction of reproductive/family planning service and influencing factors. Reproduct Contracept 2002;22:40-6.

34. Jx L, Wy S, Yy: Z. An analysis of reproductive desire of contemporary women at childbearing age, based on an investigation in 6 counties and cities in Jiangsu. J Nan Jing College Population Program Management 2011;27:21-6. 